\title{
Análisis jurídico del delito de contrabando aduanero en perjuicio efectivo al patrimonio público ecuatoriano
}

\section{Legal analysis of the crime of customs smuggling in effective damage to the Ecuadorian public heritage}

\author{
Michelle Polette Párraga-Murillo \\ dq.michelleppm42@uniandes.edu.ec \\ Universidad Regional Autónoma de los Andes \\ Ecuador \\ https://orcid.org/0000-0002-7193-9600 \\ Manacés Esaud Gaspar-Santos \\ uq.manacesgaspar@uniandes.edu.ec \\ Universidad Regional Autónoma de los Andes \\ Ecuador \\ https://orcid.org/0000-0003-4929-4495 \\ Pamilys Milagros Moreno-Arvelo \\ uq.pamilysmoreno@uniandes.edu.ec \\ Universidad Regional Autónoma de los Andes \\ Ecuador \\ https://orcid.org/0000-0001-8913-4352
}

Recepción: 01 de septiembre 2020

Revisado: 15 de octubre 2020

Aprobación: 18 de diciembre 2020

Publicación: 01 de enero 2021 


\title{
RESUMEN
}

La investigación tiene por objetivo analizar jurídicamente el delito de contrabando aduanero en perjuicio efectivo al patrimonio público ecuatoriano. Se desarrolló desde una orientación metodológica descriptiva documental con diseño bibliográfico. Desde el análisis jurídico, y a partir del objetivo de la investigación planteado; se concluye que el delito de contrabando aduanero no sólo perjudica puntos patrimoniales públicos del Estado, sino que además afecta el control del comercio exterior. Por lo tanto, el delito de contrabando es el ingreso de mercadería que llega de otro país al territorio ecuatoriano, evadiendo los controles aduaneros, de esta forma como el de provecho otorgado de forma exclusiva a las ubicaciones de menor avance, estas zonas son las ubicaciones colindantes.

Descriptores: Economía del trabajo; exportación/importación; legislación económica. (Palabras tomadas del Tesauro UNESCO).

\begin{abstract}
The objective of the investigation is to legally analyze the crime of customs smuggling to the effective detriment of the Ecuadorian public heritage. It was developed from a documentary descriptive methodological orientation with bibliographic design. From the legal analysis, and from the objective of the proposed investigation, it is concluded that the crime of customs smuggling not only damages public assets of the State, but also affects the control of foreign trade. Therefore, the crime of smuggling is the entry of merchandise that arrives from another country to Ecuadorian territory, evading customs controls, in this way as the benefit granted exclusively to the locations of less advance, these areas are the locations adjoining.
\end{abstract}

Descriptors: Labour economics; exports/imports; economic legislation. (Words taken from the UNESCO Thesaurus). 


\section{INTRODUCCIÓN}

El contrabando al ser un proceso donde se procura evadir responsabilidades aduaneras, al comercializar mercancía ilícita o la cual no posee una factura legal que la respalde, por consiguiente, el delito de contrabando "consiste en introducir al país o exportar de él productos o mercancías gravados por impuestos, sin satisfacer íntegramente esta exigencia" (Peña-Cuervo, et al., 2018, p. 33), en este sentido, podría estar presente en el momento que el vendedor, no posee ningún vínculo jurídico con la Administración Tributaria el SRI. Por lo tanto, se desconoce la procedencia de las mercancías aduciéndose en definitiva que podrían ser obtenidas de manera clandestina e ilegal lo que perjudica la recaudación tributaria al fisco y aumenta los índices de criminalidad (Cornejo, et al., 2014).

Como se ha dicho el régimen aduanero no sólo tiene la facultad jurídica de la vigilancia y regulación de sujetos, patrimonios, transporte de mercaderías, sino también el modo de recaudación de obligaciones tributarias que causa este hecho generador. Hay que mencionar, también reclamaciones, consultas, resoluciones y sanciones. Lo anterior quiere decir que tanto personas naturales y personas jurídicas nacionales como extranjeras pueden hacer importaciones a consumo y exportación a consumo en el transito aduanero.

Desde lo considerado, la concurrencia de esta conducta ilícita no sólo afecta al patrimonio del Estado, sino que también lo hace de manera extensiva a la industria nacional, y en cuanto ésta tiene incidencia decisiva en el orden económico, se entiende que también el ilícito produce efectos lesivos en bienes o intereses jurídicos de orden particular (Montenegro-Ayala, et al., 2019). Así mismo, se puede inferir que el tráfico ilegal de mercancías o el delito de contrabando aduanero, se construyó en algo tradicional para pobladores ubicados fundamentalmente en zonas costeras y límites con el Estado de Ecuador.

Esta problemática influye en el capital del Ecuador creando de esta forma una afectación a sectores comerciales e industriales, ello transciende además a la no generación de 
cobros de aranceles a mercancías enmarcadas en esta clasificación. La comisión de hechos delictivos por contrabando aduanero en diferentes los límites fronterizos del Ecuador se vino convirtiendo, en una práctica y además en una manera de supervivencia por la carencia de plazas laborales, por cuanto encuentran en este acto una más grande ocasión para crear capital superior y de una manera ligera, sin saber que el inconveniente más importante es al país de forma general.

En razón de lo planteado, la investigación tiene por objetivo analizar jurídicamente el delito de contrabando aduanero en perjuicio efectivo al patrimonio público ecuatoriano.

\section{MÉTODO}

La investigación fundamental se desarrolló desde una orientación metodológica descriptiva documental con diseño bibliográfico, lo cual permitió escrutar investigaciones y leyes relacionadas al tema de estudio, apoyándose en el método analítico - sintético con la finalidad de construir una síntesis teórica en conformidad de presentar la perspectiva investigativa del equipo investigador, para lograr tal fin, se procedió a analizar los textos seleccionados a través de la técnica de análisis de contenido jurídico, extrayéndose y analizando las principales ideas a fin de ser presentadas en la sección de análisis y discusión de los resultados.

\section{ANÁLISIS Y DISCUSIÓN DE LOS RESULTADOS}

Exploremos un poco la idea de que el ordenamiento jurídico en Ecuador, señala el nivel de intervención de sujetos implicados en el que se connota la distinción respecto al grado de penalidad de cada caso. En realidad, la norma penal de 2014 vigente en Ecuador, es ley accesoria, ello implica su aplicación ante la comisión de conductas delictivas. En efecto, la autoría por hechos delictivos en materia de aduana a un tercero lesiona la condición la condición del participe y lo incluye como como autor del delito, en este sentido; 
Desde un análisis jurídico respecto a norma tributaria se precisa que el sistema de aduana posibilita incluir en un estado, productos del exterior, de modo que al incluirse en otros modos operandis se modifican sus características, sin estar sujetas a los derechos de importación, y despachar posteriormente con los derechos de importación que correspondan a los productos transformados que resulten de estas operaciones (Coll, 2020, p.189).

En cuenta lo expuesto, es válido tener en cuenta que precisamente se generan graves perjuicios a la economía del Estado Ecuatoriano, lo cual perjudica a la construcción de nuevos servicios, creación de novedosos proyectos, ya sean centros de salud, centros académicos, entre otros de beneficio colectivo, por lo tanto, produciéndose una evasión de impuestos, lo cual perjudica a la economía del Estado, cuando esto sucede, comienza el delito no solo de contrabando aduanero si no de evasión fiscal (Sarduy-Gonzáles, 2017).

Desde lo explicado se precisan efectos negativos entre los que se tienen la posibilidad de indicar la sepa de garantía en los servicios y además en los productos, el Estado no siente capital por impuesto, la gente infringe las leyes y se deshumaniza a la sociedad, desde una pérdida axiológica del ser humano (Ávila-Morales, 2017). Es por ello que se suma la corrupción, la politización, la carencia de aptitud en técnica de aduana, la evasión de obligaciones tributarias, la falta de interés de autoridades, las pocas entidades de control de las ubicaciones fronterizas y de las vías; la falta de interés de autoridades gubernamentales, la carencia de profesionalización del Servicio de Supervisión Aduanera y la mala calidad de los servicios portuarios, lo cual genera un clima fecundo para desarrollar de modo colectivo, hechos de corrupción, siendo este un factor a considerar en la aplicación de la ley con la finalidad de contrarrestar los actos delictivos (Artaza \& Galleguillos, 2018).

Desde el criterio critico aduanero, el delito de contrabando es la más antijurídica de todas las formas de proceder y la que se le debe adjudicar más grande pena dado que no es una contravención si no un delito que tiene dentro otros delitos como la citada evasión de obligaciones tributarias, sus secuelas sobrepasan inmensamente al no cumplir las 
obligaciones formales y la defraudación, lo cual tiene lógica, por la causa que observaremos inmediatamente (Paredes-Floril, 2016). Para eso, pide como propuesta primordial que la primer parte y extracción de mercancías se ejecuta exclusiva y de forma exclusiva por determinados sitios legalmente habilitados para tales fines: las aduanas, el contrabando es un delito formal, esto tiene relación que no requiere el triunfo de cierta compañía para que se verifique (Dorfman, 2015).

\section{Derecho comparado sobre el contrabando}

Se llevó a cabo un estudio de legislación comparada tomando como referencia países fronterizos como lo es Colombia y Perú, con referente a la problemática tratada respecto al tema de referencia. De forma tal, en países como Perú la figura delictiva tratada se sanciona con pena privativa de independencia no más grande a ocho años y no menos a 5 años introduciendo a esta sanción privativa de independencia una sanción monetaria de trescientos sesenta y cinco a setecientos treinta USD de los estados unidos de América (Huamán-Sialer, 2016).

En tanto que en Colombia se lo sanciona con una lástima de cárcel de independencia no más grande a 8 años y no menor a 4 años, de esta pena de independencia se le tiene dentro una multa salarial de doscientos a trescientos por ciento del valor de los bienes que se han incautado (Hernández-Quintero \& Barrero, 2015). Desde el criterio analítico de los investigadores, se asume que esta acción en este delito de contrabando perjudica la economía del Estado ecuatoriano, peruano y colombiano.

En este sentido, en el Ecuador se debe endurecer las leyes para que se regule el pago de tributos arancelarios de un menor porcentaje, este endurecimiento de leyes debería ser fundamentada en una reducción en el pago arancelario según la mercadería que cruce la frontera, por medio de un cálculo de valores y volúmenes que tienen que ser tomados presente y puestos en la (Ley Orgánica de Aduanas 2003), y por lo tanto que a los gobernantes públicos que incurran en este delito y se hallen comprometidos y por último dar a conocer y que se coloque la iniciativa en los diferentes puntos de control 
aduanero del Ecuador, siendo necesario modernizar los procesos aduaneros en los puntos de control limítrofes, con la finalidad de evitar el fraude por contrabando (VernazaEspinosa, et al. 2020).

Se ha podido ver que las enormes poblaciones de las ubicaciones fronterizas del Ecuador se ven implicado en delitos aduaneros, los pobladores piensan que es una manera simple y ligera de conseguir ganancias superiores, fundamentalmente con el modo operandis de esta figura delictiva en Ecuador inobservando los métodos tributarios y aduaneros previstos en la legislación ecuatoriana.

\section{CONCLUSIONES}

Desde la fundamentación teórica el contrabando aduanero construyó una costumbre corriente en el vivir de los límites fronterizos del Ecuador en diferentes etapas, al no existir una sistematización de control por parte de las autoridades competentes, llegando al nivel de que las industrias pequeñas llegaron a un punto de colapsar esto se origina porque el contrabando aduanero en las ubicaciones fronterizas del Ecuador.

Desde el diagnóstico del estado de hoy y con la aplicación de la metodología de exploración se concreta que el delito de contrabando aduanero como una de las causas del perjuicio efectivo a la economía ecuatoriana, en ese sentido este delito trae consigo el resultado permanente de provocar un perjuicio al país, verificado por medio de la evasión del pago parcial o total de impuestos y de esta misma forma el cumplimiento de normas en relación a las aduanas, aunque las mercancías no sean un elemento preciso de la materia de tributación.

Desde el análisis jurídico y a partir del objetivo de la investigación planteado se concluye que el delito de contrabando aduanero no sólo perjudica puntos patrimoniales públicos del Estado, sino que además afecta el control del comercio exterior. Por lo tanto, el delito de contrabando es el ingreso de mercadería que llega de otro país al territorio ecuatoriano, evadiendo los controles aduaneros, de esta forma como el de provecho otorgado de forma exclusiva a las ubicaciones de menor avance, estas zonas son las 
ubicaciones colindantes. Esta incorporación ilícita lo ejecuta expresando frente registros aduaneros un valor menor al original de modo que facilite abonar inferiores contribuciones, al evadir la liquidación de éstos.

\section{FINANCIAMIENTO}

No monetario.

\section{AGRADECIMIENTO}

A la Universidad Regional Autónoma de los Andes, Quevedo; por motivar el desarrollo de la Investigación.

\section{REFERENCIAS CONSULTADAS}

Artaza, O, \& Galleguillos, S. (2018). El deber de gestión del riesgo de corrupción en la empresa emanado de la ley 20393 de Chile: especial referencia a las exigencias de identificación y evaluación de riesgo [The Duty to Manage the Risk of Corruption in the Company Emanated from Chilean Law 20393: Special Reference to the Identification and Risk Assessment Requirements]. Derecho PUCP, (81), 227262. https://dx.doi.org/10.18800/derechopucp.201802.008

Ávila-Morales, J. (2017). La deshumanización en medicina. Desde la formación al ejercicio profesional [Dehumanization in medicine. From training to professional practice]. latreia, 30(2),

216229. https://dx.doi.org/10.17533/udea.iatreia.v30n2a11

Coll, P. (2020). Manual de gestión aduanera. Normativa y procedimiento clave del comercio internacional [Customs management manual. Key rules and procedures of international trade]. Barcelona: Marge Books.

Cornejo, S., Suxe-Llempen, A., \& Balabarca, C. (2014). Delitos aduaneros y delito de contrabando [Customs crimes and smuggling crime]. Peru: Universidad San Andres. http://repositorio.usan.edu.pe/handle/usan/40 
Dorfman, A. (2015). Contrabando: pasar es la respuesta a la existencia de una frontera, burlar es el acto simétrico al control [Smuggling: passing is the response to the existence of a border, circumventing is the act symmetrical to control]. Aldea Mundo, 20(39),33-44.

Hernández-Quintero, H., \& Barrero, J. (2015). Evolución histórica de la legislación del delito de contrabando en Colombia [Historical evolution of the legislation of the crime of smuggling in Colombia]. Derecho Penal Y Criminología, 36(101), 1349. https://doi.org/10.18601/01210483.v36n101.02

Huamán-Sialer, M. (2016). El delito de contrabando en el Perú y en el contexto internacional [The crime of smuggling in Peru and in the international context]. $L E X$ - REVISTA DE LA FACULTAD DE DERECHO Y CIENCIAS POLÍTICAS, 14(18). http://dx.doi.org/10.21503/lex.v14i18.1245

Ley Orgánica de Aduanas, Codificación. Codificación No. 1. RO/ Sup 219 de 26 de noviembre del 2003. Compilación normas aplicables Regímenes Especiales. Recuperado de https://n9.cl/lwxmu

Montenegro-Ayala, D. P., Caza-Guevara, J. E., \& Ruiz-Rivadeneira, G. G. (2019). Control aduanero y el destino de las mercancías incautadas en la Dirección Distrital de Aduana Tulcán, periodo 2015 -2018 [Customs control and the destination of the goods seized in the District Customs Office Tulcán, period 2015 -2018]. Visión Empresarial, (9), 225-239. https://doi.org/10.32645/13906852.885

Paredes-Floril, P. (2016). Evasión tributaria vs. Mecanismos de control implementados por la administración pública [Tax evasion vs. Control mechanisms implemented by the public administration]. Revista Retos, 12(2), pp. 181-198. https://doi.org/10.17163/ret.n12.2016.04

Peña-Cuervo, J. J., Martínez-Espinosa, L. F., \& Peña-Cuervo, L. A. (2018). El delito aduanero de contrabando: identificación de los elementos de su tipo penal en Colombia [The customs crime of smuggling: identification of the elements of its criminal type in Colombia]. Prolegómenos, 21(41), 131-147. https://doi.org/10.18359/prole.2944

Sarduy-Gonzáles, M. (2017). Enfoques de análisis de la evasión fiscal. Marco conceptual [Analysis Approaches of Tax Evasion. Conceptual Framework]. Cofin Habana, 11(2), 367-386. 
Iustitia Socialis. Revista Arbitrada de Ciencias Jurídicas.

$$
\text { Año VI. Vol. VI. N 10. Enero - Junio. } 2021
$$

Hecho el depósito de Ley: FA2016000064

ISSN: 2542-3371

FUNDACIÓN KOINONIA (F.K). Santa Ana de Coro, Venezuela

Michelle Polette Párraga-Murillo; Manacés Esaud Gaspar-Santos; Pamilys Milagros Moreno-Arvelo

Vernaza-Espinosa, O., Ponce-Ruiz, D., \& Álvarez-Gómez, L. (2020). Modelo de competitividad de agentes aduaneros para la productividad del comercio exterior en el Ecuador. IUSTITIA SOCIALIS, 5(2), 821-834. http://dx.doi.org/10.35381/racji.v5i2.1070

C2021 por los autores. Este artículo es de acceso abierto y distribuido según los términos y condiciones de la licencia Creative Commons Atribución-NoComercial-Compartirlgual 4.0 Internacional (CC BY-NC-SA 4.0)

(https://creativecommons.org/licenses/by-nc-sa/4.0/). 